\title{
Analysis of the RET, GDNF, EDN3, and EDNRB genes in patients with intestinal neuronal dysplasia and Hirschsprung disease
}

R Gath, A Goessling, K-M Keller, S Koletzko, W Coerdt, H Müntefering, S Wirth, R M W Hofstra, L Mulligan, C Eng, A von Deimling

Department of Neuropathology, University of Bonn Medical Centre, D-53105 Bonn, Germany

R Gath $\dagger$

A Goessling $\dagger$

Deutsche Klinik für Diagnostik, D-65191 Wiesbaden, Germany K-M Keller

Department of Paediatrics, University of Munich, D-80336

Munich, Germany

S Koletzko

Department of Paediatric Pathology, University of Mainz

Medical Centre, D-55101 Mainz, Germany

W Coerdt

H Müntefering

Children's Hospital, D-42283 Wuppertal, Germany

S Wirth

Department of Medical Genetics, University of Groningen, 9713aw Groningen,

Netherlands

R M W Hofstra

Department of Pediatrics, Queen's University, Kingston, ON K7L 3N6, Canada L Mulligan

Clinical Cancer Genetics and Human Cancer Genetics Programs, Comprehensive Cancer Center, and Division of Human Genetics, Department of Internal Medicine, Ohio State University, Columbus, OH, USA; Cancer Research Campaign Human Cancer Genetics Research Group,

University of Cambridge, Cambridge, UK C Eng

\begin{abstract}
Background-Hirschsprung disease (HSCR) is a frequent congenital disorder with an incidence of 1 in 5000 live births, characterised by the absence of parasympathetic intramural ganglion cells in the hindgut resulting in intestinal obstruction in neonates and severe constipation in infants and adults. Intestinal neuronal dysplasia (IND) shares clinical features with HSCR but the submucosal parasympathetic plexus is affected. IND has been proposed as one of the most frequent causes of chronic constipation and is often associated with HSCR.
\end{abstract}

Methods-We examined 29 patients diagnosed with sporadic HSCR, 20 patients with IND, and 12 patients with mixed HSCR/IND for mutations in the coding regions of the RET, GDNF, EDNRB, and $E D N 3$ genes. The entire coding regions were analysed by single strand conformational polymorphism and DNA sequencing.

Results-Only three RET mutations were detected in patients with HSCR. In patients with IND or a mixed HSCR/IND phenotype, no mutations in these genes were observed. While HSCR and HSCR/ IND showed over representation of a specific RET polymorphism in exon 2 , IND exhibited a significantly lower frequency comparable with that of controls.

Conclusions-The mutation frequency found in our sporadic HSCR patients $(10 \%)$ and the allelic distribution of RET polymorphisms are comparable with earlier published data. A significantly different allelic distribution in an established HSCR associated polymorphism argues against common genetic pathways for HSCR and IND.

(Gut 2001;48:671-675)

Keywords: Hirschsprung disease; intestinal neuronal dysplasia; RET; GDNF; EDNRB; EDN3

Hirschsprung disease (HSCR) is associated with congenital absence of ganglion cells in both the myenteric and submucosal plexus along variable lengths of the distal gastrointestinal tract. According to the spatial extent of aganglionosis, long segment forms (20\%) are distinguished from short segment forms (80\%). Typically, HSCR presents in neonates or early childhood with symptoms ranging from chronic constipation to acute ileus but late manifestations in adults have occasionally been described. ${ }^{1}$ HSCR occurs in approximately 1 in 5000 live births. There is a male predominance with a sex ratio of 3.5-4.0 males to 1 female and an overall risk to siblings of $4 \%,{ }^{2} 3$ suggesting genetic factors. The disorder, which mostly occurs sporadically, is considered multifactorial with major and modifying genes. Genetic mapping in multiplex families and mutational analysis of candidate genes has led to the definitive identification of seven genes, which contribute to HSCR risk. Different forms of inheritance can be distinguished. Families with long segment as well as those with short segment HSCR mostly follow an autosomal dominant form of inheritances with incomplete penetrance. ${ }^{4}$ Sporadic HSCR variants are thought to arise as a result of multifactorial inheritance, ${ }^{3}$ whereas some HSCR variants being associated with distinct malformations, such as Waardenburg syndrome, ${ }^{5}{ }^{6}$ are mostly autosomal recessive or due to chromosomal abnormalities, as is the case in the association with Down's syndrome. ${ }^{7}$ Molecular analyses have identified mutations in the $R E T,{ }^{8-14} G D N F,{ }^{15-17} E D N 3^{18-20}$ and EDNRB ${ }^{21-24}$ genes segregating with HSCR. Common to these genes is a role in the development, migration, and survival of neural cells. Germline mutations in the receptor tyrosine kinase $R E T$ were most common and detected in $10-20 \%$ of sporadic HSCR patients ${ }^{8-12}$ although population based studies demonstrated that only $3 \%$ of isolated HSCR harboured germline RET mutations. ${ }^{14}$ Mutations in GDNF, a ligand for $R E T$, seem to occur less frequently and may not suffice to induce the clinical picture of HSCR. ${ }^{15-17} E D N R B$ mutations may account for $5-15 \%$ of HSCR cases. ${ }^{22}{ }^{23}$ The EDBRB ligand $E D N 3$ has been described as being mutated in only a few cases. ${ }^{13}{ }^{18-20}$ In addition, mutations in $N T N,{ }^{25}$ which encodes another RET ligand, account for rare HSCR cases. Furthermore, heterozygous mutations in SOX10 encoding the Sry related transcription factor have recently been reported in a few ShahWaardenburg patients. ${ }^{26}$ An ECE1 gene mutation was found in a HSCR patient, who was also diagnosed with cardiac defects and autonomic dysfunction. ${ }^{27}$

Abbreviations used in this paper: IND, intestinal neuronal dysplasia; HSCR, Hirschsprung disease; SSCP, single strand conformational polymorphism. 
Department of Neuropathology, Charité, Humboldt University, D-13353 Berlin, Germany

A von Deimling

†These authors contributed equally to this work.

Correspondence to: Dr A von Deimling, Institut für Neuropathologie, Charité, Campus

Virchow Klinikum,

Augustenburgerplatz 1, D-13353 Berlin, Germany. andreas.von_deimling@ charite.de

Accepted for publication 19 December 2000
Intestinal neuronal dysplasia (IND), which was first described in $1971,{ }^{28}$ is a heterogeneous disorder of the enteric nervous system. Estimates on the frequency of IND range from $5 \%$ to $60 \%$ of all patients biopsied for suspected motility disorders. Up to $20 \%$ of patients diagnosed with IND show the full morphology of HSCR distally. ${ }^{29}$ The most prominent histological features of IND are giant ganglia containing more than seven nerve cells. ${ }^{30}$ The aetiology of IND is unresolved, with diverse pathomechanisms, including developmental disturbances, reactive changes, or inflammatory diseases being discussed. ${ }^{31}$ The existence of IND as a clearly defined clinical and pathological entity is still a matter of intense debate. ${ }^{32} 33$ In a recent study, a high interobserver variation with regard to the diagnosis of IND was described. ${ }^{34}$

Both HSCR and IND result in motility disturbances and constipation. A malfunction in the development of the enteric nervous system seems to play an important role in the aetiology of these clinically similar diseases. ${ }^{35}{ }^{36}$ Because IND and HSCR occur in combination, it may be possible that the molecular defects occurring in patients with HSCR may also be causative for IND. RET is viewed as the major susceptibility gene for HSCR but two IND families did not show linkage to RET on chromosome $10 .{ }^{37}$ However, because of the problematic clinical characterisation of IND, possibly resulting from heterogeneity, and the existence of additional HSCR associated genes, common molecular pathways in the genesis of HSCR and IND cannot be excluded.

To investigate the potential role of the HSCR associated RET, GDNF, EDNRB, and EDN3 genes in the development of IND, we performed mutation analysis of these genes in a series of 29 patients diagnosed with HSCR, 20 with IND, and 12 with combined HSCR/IND.

\section{Materials and methods}

PATIENTS AND CONTROL SAMPLES

Peripheral blood samples were obtained from 61 unrelated sporadic patients and 14 first degree relatives (11 parents and three sibs from eight patients) treated at the University Hospitals Bonn, Dusseldorf, Freiburg, Heidelberg, Mainz, Munich, Children's Hospitals Lippstadt, Mannheim, Protestant Jung-Stilling Hospital Siegen, Protestant Hospital Oberhausen, and Marien-Hospital, Bonn. HSCR was diagnosed in 29 patients, IND in 20, and a combined HSCR/IND phenotype in 12. Each case was classified by members of the German Hirschsprung Reference Group (WC, HM). The diagnosis was based on guidelines agreed on at a consensus meeting. ${ }^{30}$ Blood DNA serving as control samples was obtained from a pool of anonymous donors. DNA was extracted according to standard protocols. All patients and controls consented to molecular analyses.

SSCP ANALYSIS AND DIRECT SEQUENCING The primers and conditions for polymerase chain reaction mediated amplification of the exons of the $R E T,{ }^{38} G D N F,{ }^{39} E D N R B,{ }^{40}$ and
$E D N 3^{20}$ genes have been published previously. Polymerase chain reaction was performed in a final volume of $10 \mu \mathrm{l}$ containing $10 \mathrm{ng}$ of DNA, $50 \mathrm{mM} \mathrm{KCl}, 10 \mathrm{mM}$ Tris $\mathrm{HCl}, \mathrm{pH} 8.3,200$ $\mathrm{mM}$ of each dNTP, $0.1 \%$ gelatin, $20 \mathrm{pmol}$ of each primer, and 0.25 units of Taq polymerase. $\mathrm{MgCl}_{2}$ concentrations ranged from 1.0 to 2.0 $\mathrm{mM}$ depending on the primer pair. Initial denaturation at $95^{\circ} \mathrm{C}$ for three minutes was followed by 30 cycles on an automated thermocycler (Omnigene; Hybaid Ltd, Ashford, Middlesex, UK). These included denaturation at $95^{\circ} \mathrm{C}$ for 30 seconds, annealing at temperatures of $52-58^{\circ} \mathrm{C}$ for 40 seconds, and extension at $72^{\circ} \mathrm{C}$ for 30 seconds. A final extension step of 10 minutes at $72^{\circ} \mathrm{C}$ was added. Single strand conformational polymorphism (SSCP) analysis was carried out on long acrylamide gels (6-14\% acrylamide, $0-10 \%$ glycerol, $1 \times \mathrm{TBE})$ on a sequencing apparatus (Pokerface; Hoefer Scientific, San Francisco, California, USA) at room temperature or at $4^{\circ} \mathrm{C}$ with $2-20 \mathrm{~W}$. For detection of amplified products, a silver stain protocol was used. ${ }^{41}$ Variant SSCP bands were excised and DNA was extracted followed by reamplification and direct sequencing. All aberrantly migrating fragments were sequenced bidirectionally. Sequence analysis was carried out with a semiautomated sequencer (Applied Biosystem, Foster City, California, USA, model 373A) and a Taq cycle sequencing kit.

\section{Results}

ALTERATIONS IN RET

Three germline sequence variants were detected in RET. Of these, one was a $3 \mathrm{bp}$ deletion in exon 3 affecting the sequence TCTCCTT at nucleotides 635-642, allowing for deletion of CTC, TCC, or CCT, all resulting in loss of a serine moiety at codon 148. (Base pair positions relative to the RET coding sequence are numbered from the transcription start site, as defined by Itoh and colleagues ${ }^{42}$ and Kwok and colleagues ${ }^{43}$.) A germline missense mutation was found in exon 15 at nucleotide $2813 \mathrm{G} \rightarrow \mathrm{A}$ resulting in a $\mathrm{R} 873 \mathrm{Q}$ exchange in codon 873 . The third alteration affected intron 14 and was characterised by a $\mathrm{G} \rightarrow \mathrm{A}$ exchange localised at the putative branch site 24 nucleotides in front of exon 15. All three mutations occurred in patients with HSCR. Parental or sibling DNA from these three patients was not available. No RET mutations were seen in patients with IND or mixed HSCR/IND. None of these alterations was detected in 300 alleles from 150 unaffected control individuals. Thus these three alterations were interpreted as disease causing mutations.

\section{POLYMORPHISMS}

Conservative nucleotide polymorphisms were detected in exons $2,3,7,13$, and 15 of the RET protooncogene (table 1). These alterations have been described previously. ${ }^{38}$ Allele 390 A of the exon 2 polymorphism has previously been shown to be over represented in patients with HSCR. ${ }^{44}{ }^{45}$ Allel $390 \mathrm{~A}$ in exon 2 exhibited a frequency of 0.770 in the patient group. 
Table 1 Polymorphisms in RET and EDNRB genes

\begin{tabular}{|c|c|c|c|c|c|c|c|}
\hline \multirow[b]{2}{*}{ Gene } & \multicolumn{2}{|c|}{ Alleles in controls } & \multicolumn{2}{|c|}{ Alleles in patients } & \multirow[b]{2}{*}{ Position } & \multirow[b]{2}{*}{ Nucleotide } & \multirow[b]{2}{*}{ Amino acid } \\
\hline & No & Frequency & No & Frequency & & & \\
\hline$R E T$ & 29 & 0.141 & 94 & 0.770 & Exon 2 & $390 \mathrm{~A}$ & $45 \mathrm{~A}$ \\
\hline$R E T$ & 177 & 0.859 & 28 & 0.230 & & $390 \mathrm{G}$ & $45 \mathrm{~A}$ \\
\hline$R E T$ & - & - & 121 & 0.992 & Exon 3 & $570 \mathrm{C}$ & $125 \mathrm{~V}$ \\
\hline$R E T$ & - & - & 1 & 0.008 & & $570 \mathrm{~A}$ & $125 \mathrm{~V}$ \\
\hline$R E T$ & - & - & 77 & 0.631 & Exon 7 & $1491 \mathrm{G}$ & $432 \mathrm{~A}$ \\
\hline$R E T$ & - & - & 45 & 0.369 & & $1491 \mathrm{~A}$ & $432 \mathrm{~A}$ \\
\hline$R E T$ & - & - & 75 & 0.615 & Exon 13 & $2502 \mathrm{C}$ & $769 \mathrm{~L}$ \\
\hline$R E T$ & - & - & 47 & 0.385 & & $2502 \mathrm{G}$ & $769 \mathrm{~L}$ \\
\hline$R E T$ & - & - & 92 & 0.754 & Exon 15 & $2907 \mathrm{C}$ & $904 \mathrm{~S}$ \\
\hline$R E T$ & - & - & 30 & 0.246 & & $2907 \mathrm{G}$ & $904 \mathrm{~S}$ \\
\hline$E D N R B$ & 54 & 0.931 & 106 & 0.883 & Exon 1 & ATG-148A & 5' UTR \\
\hline$E D N R B$ & 4 & 0.069 & 14 & 0.117 & & ATG-148G & 5' UTR \\
\hline$E D N R B$ & 48 & 0.857 & 109 & 0.924 & Exon 1 & $\mathrm{c} 169 \mathrm{G}$ & $57 \mathrm{G}$ \\
\hline$E D N R B$ & 8 & 0.143 & 9 & 0.076 & & $\mathrm{c} 169 \mathrm{~A}$ & $57 \mathrm{~S}$ \\
\hline$E D N R B$ & 49 & 0.875 & 96 & 0.828 & Exon 4 & $\mathrm{c} 818 \mathrm{~A}+\mathrm{c} 875 \mathrm{~T}$ & $273 \mathrm{~K}+292 \mathrm{~F}$ \\
\hline$E D N R B$ & 7 & 0.125 & 20 & 0.172 & & $\mathrm{c} 818 \mathrm{G}+\mathrm{c} 875 \mathrm{G}$ & $273 R+292 C$ \\
\hline
\end{tabular}

Allele frequencies, nucleotides affected, and amino acid exchange are given for the observed polymorphisms of the respective genes. - , not examined.

However, the frequency for 390 A differed between patients with HSCR $(\mathrm{f}=0.750)$, HSCR/IND ( $\mathrm{f}=0.916)$, and IND $(\mathrm{f}=0.250)$. There was no significant difference between HSCR and HSCR/IND patients but a significant difference was found between patients with HSCR and IND (Fisher's exact test; $\mathrm{p}<0.01$ ), and between patients with HSCR/ IND and IND (Fisher's exact test; $\mathrm{p}<0.01$ ). A control group exhibited 390 A with a frequency of 0.141 . In $E D N R B$, four polymorphisms were detected: one in the untranslated region of exon 1 , one in the coding portion of exon 1 , and two in exon 4 . The polymorphisms in exon 4 were in linkage disequilibrium. No sequence changes indicated by abnormal SSCP patterns were found in the $E D N R B, E D N 3$, or GDNDF genes. All EDNRB polymorphisms were seen in a panel of control individuals exhibiting similar frequencies as the patients.

\section{Discussion}

In the present study, we investigated germline DNA from 29 patients with sporadic Hirschsprung disease (HSCR), 20 with intestinal neuronal dysplasia (IND), and 12 with a mixed HSCR/IND phenotype for mutations in the $R E T, G D N F, E D N R B$, and EDN3 genes. Three RET mutations were detected in HSCR patients whereas no such alterations were seen in IND and HSCR/IND patients.

RET mutations constitute the most frequently observed genetic alteration in patients with HSCR disease. The frequency ranges from $0 \%$ to $50 \%$ in sporadic cases..$^{10-12} 1446$ In general, studies on sporadically occurring HSCR yielded lower frequencies of RET mutations than studies on familial disease. The frequency of $R E T$ mutations in the present study was $10 \%$ in patients diagnosed with HSCR, matching values in previous studies. No RET mutations were detected in patients with IND or mixed HSCR/IND. While the difference in the number of RET mutations between HSCR patients and those diagnosed with IND or mixed HSCR/IND was not significant, it indicates that this mutation is not a major factor in the pathogenesis of IND. There are several possible explanations for our relatively low detection rate. RET mutations were frequently seen in up to $50 \%$ of patients with familial forms of HSCR. In our study, no patient with a positive history for familial HSCR was enrolled, possibly accounting for the reduced number of mutations in the RET gene. While the sensitivity of SSCP may account for varying detection rates, we identified several polymorphisms previously described. ${ }^{38}$ However, a frequent polymorphism (G691S) was not detected by our assay, emphasising the limitations of SSCP analysis.

Recent studies revealed that allele 390 A of the exon 2 polymorphism is over represented in patients with HSCR. ${ }^{44}{ }^{45}$ Our data support these findings as both groups (HSCR and HSCR/IND patients) exhibited allele $390 \mathrm{~A}$ in a comparable frequency. In contrast, IND patients had a frequency for $390 \mathrm{~A}$ in the range of that detected in a control group. Both HSCR and HSCR/IND patients carried this allele significantly more often than IND patients. Our findings may suggest that IND is genetically different from HSCR. This hypothesis is further supported by a recent study challenging IND as a defined pathological process and suggesting that IND may in part represent a normal variant of development. ${ }^{34}$

Occasional mutations in the GDNF gene were observed in HSCR patients. ${ }^{15-17}$ GDNF has been identified as a ligand of a multicomponent receptor system consisting of GFRA1 and $R E T .^{47-50}$ In our series, no GDNF mutations were seen in HSCR, IND, or mixed HSCR/IND patients. A recent study based on 269 patients, including the patients in this series, revealed no mutations in GFRA $1 .{ }^{51}$ One study suggested that germline mutations of GDNF are not sufficient to cause HSCR but may play a role as a modulating factor with other susceptibility loci such as the RET gene. ${ }^{17}$ Therefore, a concept of genes synergistically cooperating in generating a HSCR phenotype was promoted. ${ }^{22}$ This hypothesis is supported by the incomplete penetrance in familial HSCR which may result from the presence of modifier genes..$^{52} 53$

Besides a missense mutation of EDNRB detected in the Mennonite pedigree, further 
variants have been identified in familial and sporadic cases of HSCR. However, they only account for a few cases. The homozygous status of $E D N R B$ mutations is likely to be associated with syndromic HSCR whereas the heterozygous status appears to play a role in the development of non-syndromic HSCR. ${ }^{54}$ In our series, no mutations were detected, stressing the minor role of EDNRB in HSCR. Also, $E D N R B$ does not seem to be responsible for the pathogenesis of IND.

No mutations in the EDN3 gene were detected in our series. The rate of mutations of $E D N 3$ in patients with HSCR is approximately $1 \%$. Among the reported gene alterations, mutations in Shah-Waardenburg syndrome are homozygous, whereas heterozygous carriers in these families may only be affected by depigmentation and deafness with incomplete penetrance. ${ }^{18}$ In sporadic non-syndromic HSCR, heterozygous mutations are found in this gene. However, mutations in the END3 gene may not be sufficient or necessary to cause HSCR but may act more as modifier genes. ${ }^{55}$ Whether other as yet unidentified genes are responsible for the development of HSCR is open to question as there are various reports on repeated chromosomal abnormalities..$^{56} 57$

In conclusion, a set of patients including 29 with HSCR, 20 with IND, and 12 with mixed HSCR/IND was systematically analysed for genes involved in the pathogenesis of HSCR. The data support the fact that HSCR is a clinically well defined disease with $R E T$ mutations being the most frequently detected disease associated genetic alteration, with over representation of RET allele $390 \mathrm{~A}$. However, the overall frequency of mutations detected in sporadic HSCR was low and allows for other, as yet unidentified, genetic mechanisms. In addition, our data indicate that IND may be genetically different from HSCR and may support the recently assumption ${ }^{34}$ that IND does not constitute a clinically and histopathologically well defined disease.

The authors thank B Meyer-Puttlitz and U Laß for skilful technical assistance. Supported by the Hermann und Lilly Schilling Foundation (to AvD) and P30CA16058 from the National Cancer Institute, Bethesda, MD (to the Ohio State University Comprehensive Cancer Center).

1 Lesser PB, El-Nahas AM, Lukl P, et al. Adult-onset Hirschsprung's disease. $7 A M A$ 1979;242:747-8.

2 Goldberg EL. An epidemiological study of Hirschsprung's disease. Int F Epidemiol 1984:13:479-85.

3 Badner JA, Sieber WK, Garver KL, et al. A genetic study of Hirschsprung disease. Am f Hum Genet 1990;46:568-80.

4 Edery P, Pelet A, Mulligan LM, et al. Long segment and Edery P, Pelet A, Mulligan LM, et al. Long segment and
short segment familial Hirschsprung's disease: variable short segment familial Hirschsprung's disease: variable
clinical expression at the RET locus. F Med Genet 1994;31: clinical

5 Badner JA, Chakravarti A. Waardenburg syndrome and Hirschsprung disease: evidence for pleiotropic effects of a single dominant gene. Am $\mathcal{F}$ Med Genet 1990;35:100-4

6 Omenn GS, McKusick VA. The association of Waardenburg syndrome and Hirschsprung megacolon. Am f Med Genet 1979;3:217-23.

7 Leung AK, Seagram GF. Hirschsprung's disease and mongolism. F Natl Med Assoc 1991;83:660.

8 Edery P, Lyonnet S, Mulligan LM, et al. Mutations of the RET proto-oncogene in Hirschsprung's disease. Nature 1994;367:378-80.

9 Romeo G, Ronchetto P, Luo Y, et al. Point mutations affecting the tyrosine kinase domain of the RET proto-oncogene in Hirschsprung's disease. Nature 1994;367:377-8.

10 Yin L, Barone V, Seri M, et al. Heterogeneity and low detection rate of RET mutations in Hirschsprung disease. Eur $\mathcal{F}$ Hum Genet 1994;2:272-80.
11 Angrist $\mathrm{M}$, Bolk S, Thiel B, et al. Mutation analysis of the RET receptor tyrosine kinase in Hirschsprung disease. Hum Mol Genet 1995;4:821-30.

12 Attie T, Pelet A, Edery P, et al. Diversity of RET proto-oncogene mutations in familial and sporadic Hirschsprung disease. Hum Mol Genet 1995;4:1381-6.

13 Kusafuka T, Wang Y, Puri P. Mutation analysis of the RET, the endothelin-B receptor, and the endothelin-3 genes in sporadic cases of Hirschsprung's disease. 7 Pediatr Surg 1997;32:501-4

14 Svensson PJ, Molander ML, Eng C, et al. Low frequency of RET mutations in Hirschsprung disease in Sweden. Clin Genet 1998;54:39-44.

15 Ivanchuk SM, Myers SM, Eng C, et al. De novo mutation of GDNF, ligand for the RET/GDNFR-alpha receptor complex, in Hirschsprung disease. Hum Mol Genet 1996;5: 2023-6.

16 Angrist M, Bolk S, Halushka M, et al. Germline mutations in glial cell line-derived neurotrophic factor (GDNF) and RET in a Hirschsprung disease patient. Nat Genet 1996;14:341-4

17 Salomon R, Attie T, Pelet A, et al. Germline mutations of the RET ligand GDNF are not sufficient to cause Hirschsprung disease. Nat Genet 1996;14:345-7.

18 Hofstra RM, Osinga J, Tan-Sindhunata G, et al. A homozygous mutation in the endothelin-3 gene associated with a combined Waardenburg type 2 and Hirschsprung phenotype (Shah-Waardenburg syndrome). Nat Genet phenotype (Sh

19 Edery P, Attie T, Amiel J, et al. Mutation of the endothelin-3 gene in the Waardenburg-Hirschsprung disease (ShahWaardenburg syndrome). Nat Genet 1996;12:442-4.

20 Bidaud C, Salomon R, Van Camp G, et al. Endothelin-3 gene mutations in isolated and syndromic Hirschsprung disease. Eur F Hum Genet 1997;5:247-51.

21 Puffenbeger EG, Hosoda K, Washington SS, et al. A missense mutation of the endothelin-B receptor gene in multigenic Hirschsprungs disease. Cell 1994;79:1257-66.

22 Auricchio A, Casari G, Staiano A, et al. Endothelin-B receptor mutations in patients with isolated Hirschsprung tor mutations in patients with isolated Hirschsprung disease from a

23 Kusafuka T, Wang Y, Puri P. Novel mutations of the endothelin-B receptor gene in isolated patients with Hirschsprung's disease. Hum Mol Genet 1996;5:347-9.

24 Chakravarti A. Endothelin receptor-mediated signaling in Hirschsprung disease. Hum Mol Genet 1996;5:303-7.

25 Doray B, Salomon R, Amiel J, et al. Mutation of the RET ligand, neurturin, supports multigenic inheritance in
Hirschsprung disease. Hum Mol Genet 1998;7:1449-52.

26 Pingault V, Bondurand N, Kuhlbrodt K, et al. SOX10 mutations in patients with Waardenburg-Hirschsprung disease. Nat Genet 1998;18:171-3.

27 Hofstra RM, Valdenaire O, Arch E, et al. A loss-of-function mutation in the endothelin-converting enzyme 1 (ECE-1) mutation in the endothelin-converting enzyme 1 (ECE-1) associated with Hirschsprung disease, cardiac defects, and

28 Meier-Ruge W. Über ein Erkrankungsbild des Colon mit Hirschsprungsymptomatik. (Causes of colon disorder with symptoms of Hirschsprung's disease). Verh Dtsch Ges Pathol 1971;55:506-10

29 Fadda B, Maier WA, Meier-Ruge W, et al. Neuronale intestinale Dysplasie: Eine kritische 10. Jahress Analyse plasia. Critical 10-years' analysis of clinical and biopsy

30 Borchard F, Meier-Ruge W, Wiebecke B, et al. Innervationsstörungen des Dickdarms: Klassifikation und Diagnostik (Disorders of the innervation of the large intestine: classification and diagnosis). Pathologe 1991;12:171-4.

31 Sacher P, Briner J, Hanimann B. Is neuronal intestinal dysplasia (NID) a primary disease or a secondary phenomenon? Eur F Pediatr Surg 1993;3:228-30.

32 Meier-Ruge W, Gambazzi F, Kaufeler RE, et al. The neuropathological diagnosis of neuronal intestinal dysplasia (NID B). Eur f Pediatr Surg 1994;4:267-73.

33 Berry CL. Intestinal neuronal dysplasia: does it exist or has it been invented? Virchows Archiv A Pathol Anat 1993;422: $183-4$.

34 Koletzko S, Jesch I, Faus-Keßler T, et al. Rectal biopsy for diagnosis of intestinal neuronal dysplasia in children: a prospective multicentre study on interobserver variation and clinical outcome. Gut 1999;44:853-61.

35 Holschneider AM, Meier-Ruge W, Ure BM. Hirschsprung's disease and allied disorders - a review. Eur $\mathcal{F}$ Pediatr Surg 1994:4:260-6.

36 Martucciello G, Favre A, Takahashi M, et al. Immunohistochemical localization of RET protein in Hirschsprung's disease. F Pediatr Surg 1995;30:433-6.

37 Barone V, Weber D, Luo Y, et al. Exclusion of linkage between RET and neuronal intestinal dysplasia type B. Am f Med Genet 1996;62:195-8.

38 Ceccherini I, Hofstra R, Luo Y, et al. DNA polymorphisms and conditions for SSCP analysis of the 20 exons of the ret proto-oncogene. Oncogene 1994;9:3025-9.

39 Dahia PL, Toledo SP, Mulligan LM, et al. Mutation analysis of glial cell line-derived neurotrophic factor (GDNF), a ligand for the RET/GDNF receptor alpha complex, in sporadic phaeochromocytomas. Cancer Res 1997;57:31013 .

40 Arai H, Nakao K, Takaya K, et al. The human endothelin-B receptor gene. Structural organization and chromosomal assignment. F Biol Chem 1993;268:3463-70. 
41 von Deimling A, Bender B, Louis DN, et al. A rapid and non radioactive PCR based assay for the detection of allelic loss in human gliomas. Neuropathol Appl Neurobiol 1993;19: $524-9$

42 Itoh F, Ishizaka $\mathrm{Y}$, Tahira $\mathrm{T}$, et al. Identification and analysis of the RET proto-oncogene promoter region in neuroblastoma cell lines and medullary thyroid carcinomas from MEN 2A patients. Oncogene 1992;7:1201-6.

43 Kwok JBJ, Gardner E, Warner JP, et al. Sructural analysis of the human RET proto-oncogene using exon trapping. Oncogene 1993;8:2575-82.

44 Borrego S, Saez ME, Ruiz A, et al. Specific polymorphisms in the RET proto-oncogene are over-represented in patients with Hirschsprung disease and may represent loci modifying phenotypic expression. F Med Genet 1999;36: $771-4$.

45 Fitze G, Schreiber M, Kuhlisch E, et al. Association of RET protooncogene codon 45 polymorphism with Hirschsprotooncogene codon 45 polymorphism with

46 Sancandi M, Ceccherini I, Costa M, et al. Incidence of RET mutations in patients with Hirschsprung's disease. F Pediatr murg 2000;35:139-42.

47 Durbec P, Marcos Gutierrez CV, Kilkenny C, et al. GDNF signalling through the Ret receptor tyrosine kinase. Nature 1996;381:789-93.

48 Trupp M, Arenas E, Fainzilber M, et al. Functional receptor for GDNF encoded by the c-ret proto-oncogene. Nature 1996;381:785-8.
49 Treanor JJ, Goodman L, de Sauvage F, et al. Characterization of a multicomponent receptor for GDNF. Nature tion of a multico

50 Jing S, Wen D, Yu Y, et al. GDNF-induced activation of the RET protein tyrosine kinase is mediated by GDNFRalpha, a novel receptor for GDNF. Cell 1996;85:1113-24.

51 Myers SM, Salomon R, Gössling A, et al. Investigation of germline GFR alpha-1 mutations in Hirschsprung disease. $\mathscr{f}$ Med Genet 1999;36:217-20.

52 Romeo G, McKusick VA. Phenotypic diversity, allelic series and modifier genes. Nat Genet 1994;7:451-3.

53 Bolk S, Pelet A, Hofstra RM, et al. A human model for multigenic inheritance: phenotypic expression in Hirschsprung disease requires both the RET gene and a new $9 \mathrm{q} 31$ locus. Proc Natl Acad Sci USA 2000;97:268-73.

54 Kusafuka T, Puri P. Genetic aspects of Hirschsprung's disease. Semin Pediatr Surg 1998;7:148-55.

55 Svensson PJ, Von Tell D, Molander ML, et al. A heterozygous frameshift mutation in the endothelin-3 heterozygous frameshift mutation in the endothelin-3 Res 1999;45:714-7.

56 Webb GC, Keith CG, Campbell NT. Concurrent de novo interstitial deletion of band $2 \mathrm{p} 22$ and reciprocal translocation $(3 ; 7)(\mathrm{p} 21 ; \mathrm{q} 22)$. F Med Genet 1988;25:125-7.

57 Beedgen B, Nutzenadel W, Querfeld U, et al. "Partial trisomy 22 and 11 " due to a paternal 11;22 translocation associated with Hirschsprung disease. Eur 7 Pediatr 1986;145:229-32.

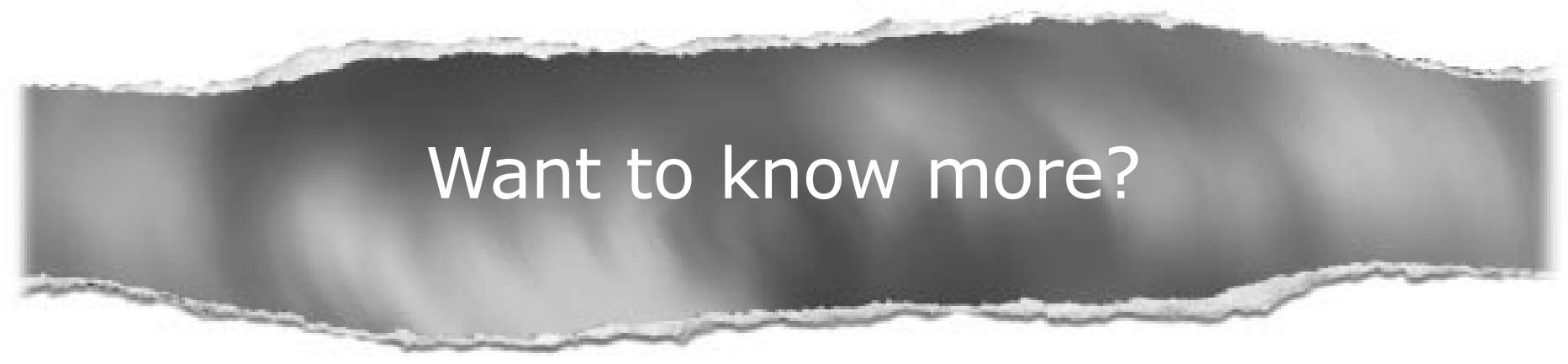

Data supplements

Limited space in printed journals means that interesting data and other material are often edited out of articles; however, limitless cyberspace means that we can include this information online.

Look out for additional tables, references, illustrations.

www.gutjnl.com 